\title{
Productivity Loss and Associated Costs Among Employed Patients Receiving Disease-Modifying Treatment for Multiple Sclerosis
}

\author{
Machaon Bonafede ${ }^{1} \cdot$ Rina Mehta $^{2} \cdot$ Gilwan Kim $^{1} \cdot$ Ila Sruti $^{1} \cdot$ Marc Tian $^{2} \cdot$ Corey Pelletier $^{2} \cdot$ Neil Goldfarb $^{3}$
}

Accepted: 19 September 2020 / Published online: 13 October 2020

(c) The Author(s) 2020

\begin{abstract}
Objectives The aim of this study was to examine the indirect burden of employed multiple sclerosis (MS) patients initiating disease-modifying therapies (DMTs) in the US.

Methods DMT-treated MS patients (DMT users) and direct-matched controls without MS (1:3) were captured using the IBM MarketScan Commercial Claims and Encounters Database and the Health and Productivity Management Database between 1 January 2009 and 1 January 2017. DMT users were also stratified by route of administration. Time loss and costs from absenteeism, short-term disability, and long-term disability were assessed for DMT users and matched controls.

Results A total of 3022 DMT users were matched to 9066 controls. Compared with injectable DMT users, oral DMT users took twice as long to initiate therapy but had numerically lower absenteeism costs and significantly lower long-term disability costs in the first year after DMT initiation. The mean (standard deviation) indirect costs of absenteeism, short-term disability, and long-term disability were US\$6474 (US\$6779), US\$2368 (US\$5777), and US\$280 (US\$2578), respectively, for DMT users and US\$4468 (US\$3814), US\$328 (US\$1950), and US\$36 (US\$938), respectively, for controls in the first year (all $p<0.001$ ). Conclusions Employed DMT users in the US incurred incremental increased indirect burden ( $\$ 2007$ in absenteeism, \$2040 in short-term disability, and \$244 in long-term disability) compared with matched controls. Despite evidence of delays in treatment initiation, oral DMT users had evidence of reduced work loss compared with injectable users, suggesting that open access to all treatment options may reduce the indirect burden of MS. Additional research into the impact of route of administration on the burden of long-term disability among MS patients is needed.
\end{abstract}

\section{Key Points for Decision Makers}

Among patients treated with DMTs, the indirect burden of MS is high compared with controls.

The route of administration of the DMT initiated may impact the indirect burden of MS.
Electronic supplementary material The online version of this article (https://doi.org/10.1007/s41669-020-00233-8) contains supplementary material, which is available to authorized users.

Gilwan Kim

kimgi@us.ibm.com

1 IBM Watson Health, 75 Binney St, Cambridge, MA 02142, USA

2 Bristol-Myers Squibb Company, Princeton, NJ, USA

3 Greater Philadelphia Business Coalition on Health, Philadelphia, PA, USA

\section{Introduction}

Multiple sclerosis (MS) is a chronic autoimmune disease resulting in demyelination of axons and other injuries to multiple body systems [1]. The 2017 US prevalence of MS was an estimated 337.9-362.6 per 100,000 or roughly 900,000 individuals [2]. Most MS patients are diagnosed between the ages of 20-40 years [3]. In a US study, prevalence was highest in 
the group aged 55-64 years [2]. Since MS is diagnosed at a relatively young age, it substantially impacts productivity and employment [4]. MS presents heterogeneously and progresses at different rates with four classical presentation types, including clinically isolated syndrome (CIS), relapsing-remitting, secondary progressive, and primary progressive $[5,6]$. The disease is pharmacologically managed with disease-modifying therapies (DMTs) and/or symptomatic treatments.

Early treatment of MS with DMTs can reduce conversion from CIS to MS, reduce relapses, and delay conversion from relapsing-remitting to secondary progressive MS [7, 8]. DMTs are delivered through three routes of administration (ROAs; i.e., injection, infusion, and oral), and while the first injectable DMT was approved in 1993, the first oral DMT was not approved until 2010 [7]. Currently, guidance is limited for selecting a DMT for MS patients $[8,9]$. As a result, key factors in decision making are highly individualized and may include the severity of disease at presentation, patient prognostic factors, medication risk/benefit profile, prior treatment, treatment schedule, and ROA [9-11]. In surveys of patients with MS, other factors being equal, a daily oral administration was preferred to any parenteral ROA [12-14].

MS contributes to high direct and indirect costs [15-18]. Cognitive impairment, fatigue, and motor dysfunction mediate the impact of disability on employment and productivity [19, 20]. Patients with MS had higher use of long- and short-term sick leave and associated costs than those without MS [21]. In particular, relapses produce a sustained impact on disability, and a reduction in relapses positively affects disability and translates into improved health-related quality of life and fewer lost work days [22, 23].

Studies have demonstrated that MS patients are more likely to take disability time, have greater medically related absenteeism, and are less likely to be employed than matched controls [21, 24]. A 2009 study estimated the risk-adjusted annual incremental costs of disability and medically related absenteeism due to MS at US\$3501; however, this estimate has not been updated since the release of newer oral DMTs [21]. The current study used administrative claims data to quantify the indirect burden of MS in the employed patient population by comparing absenteeism, short-term disability, and long-term disability utilization between MS patients initiating DMTs and control patients without MS. We also assessed the indirect burden and cost by ROA of DMT.

\section{Methods}

\subsection{Study Design and Data Sources}

This was a retrospective, administrative claims-based US study that examined productivity loss and associated indirect costs among commercially insured adults receiving a DMT for MS.

De-identified longitudinal patient data were extracted from the IBM MarketScan Commercial Claims and Encounters Database and the IBM MarketScan Health and Productivity Management (HPM) Database. The Commercial database captures inpatient medical, outpatient medical, and outpatient prescription drug data of 145.5 million employees and their dependents covered under a variety of fee-for-service and managed care health plans. The Health and Productivity Management database contains workplace absence, short-term disability, and long-term disability data for a subset of employer clients that contribute data to the Commercial database. The productivity data are available for the primary beneficiary (employee) only, not other adult family members. The data are fully linkable to healthcare claims, allowing analysis of the impact of different treatments on patient productivity.

All study data were obtained using International Classification of Diseases, 9th and 10th Revision, Clinical Modification (ICD-9-CM and ICD-10-CM) codes, Current Procedural Terminology, 4th edition, codes, Healthcare Common Procedure Coding System codes, and National Drug Codes.

All database records are de-identified and certified to be fully compliant with US patient confidentiality requirements in the Health Insurance Portability and Accountability Act of 1996. Because this study used only de-identified patient records and did not involve the collection, use, or transmittal of individually identifiable data, Institutional Review Board approval was not necessary.

\subsection{Patient Selection and Cohort Matching}

MS patients on DMT ('DMT users') were included if they had (1) two or more claims (1-365 days apart) with a diagnosis of MS between January 1, 2009, and January 1, 2017, (2) no evidence of MS in the 12 months before the first MS claims, (3) one or more claims for an MS DMT on or after the first MS claim and no claims for a DMT in the 12 months prior (index date was set as the date of the first DMT claim), and (4) 12 or more months of continuous healthcare enrollment prior to the index date (baseline period) and absenteeism, short-term disability or long-term disability eligibility in any calendar year on or after the index date. Only claims that contain a definitive diagnosis of MS were included when identifying patients with a diagnosis of MS and claims that were associated solely with the diagnostic process, such as claims for lab tests or imaging procedures, were not included. Patients were excluded from the study if they had more than one DMT on the index date or had evidence of pregnancy or primary malignancy anytime during the study period. DMT users were further stratified by ROA (oral, injection, or infusion) of their index medication 
(Supplementary Table 1, see electronic supplementary material [ESM]). The population of all MS patients, regardless of evidence of a history of MS or DMT use but meeting all other criteria, was also identified.

Controls were selected from the population of individuals without any diagnostic or non-diagnostic MS claims, any claims for a DMT, any evidence of pregnancy, or any evidence of malignancy during the entire study period. The index date for controls was randomly assigned while maintaining the index date distribution by day of the MS cases. Controls were required to have 12 or more months of continuous healthcare enrollment prior to the index date (baseline period) and absenteeism, short-term disability or long-term disability eligibility in any calendar year on or after index date. Controls were exact matched to DMT users at a ratio of 3:1 based on age group, sex, geographic region, health plan type, index year, and urban/rural residence as measured on the index date.

\subsection{Outcomes and Explanatory Variables}

Annual eligibility flags (yes/no) in the HPM database are available for each of type of absence (e.g., absenteeism, short-term disability, long-term disability). The primary outcomes included missed hours (or days) from absenteeism, short-term disability, and long-term disability, and their associated indirect costs during the first calendar year of HPM eligibility after the index date and the most recent calendar year of HPM eligibility after the index date for both the DMT users and matched controls. These two time periods (i.e., first calendar year and most recent calendar year) were selected to assess the productivity trends closest and farthest from the first MS diagnosis. In the main analysis, patient eligibility was established independently for each outcome. For example, a patient needed only to have absenteeism coverage to be included in the absenteeism analysis. As a sensitivity analysis, absenteeism, short-term disability, and long-term disability for the first calendar year and the most recent calendar year were assessed for the subset of patients whose employers provided coverage for all three.

Indirect costs of absenteeism were calculated based on the estimated average hourly wage of US\$26.47, which is the 2017 Bureau of Labor Statistics average hourly earnings of all employees on private nonfarm payrolls, seasonally adjusted. Indirect costs of short-term and long-term disability were adjusted to $70 \%$ of the daily wage to reflect the fact that the short-term disability programs generally only pay out a proportion of employees' wages, which is generally capped at 70\% [25].

Baseline demographic characteristics were measured on the index date and included age, sex, geographic region, health plan type, index year, and urban/rural residence. Baseline clinical characteristics were measured during the 12-month baseline period and included Deyo-Charlson Comorbidity Index (DCI), medications (class 1A/3 antiarrhythmics, antidepressant, benzodiazepine, leflunomide, opioid), and comorbid conditions (second-/third-degree atrioventricular block, active hepatitis B, cholangitis, congestive heart failure, HIV, long QT syndrome, progressive multifocal leukoencephalopathy, sick sinus syndrome, and stroke). These comorbid conditions were selected because their presence may preclude the use of a DMT. The number of days between the earliest MS claim and the earliest MS DMT claim was also measured in DMT users.

Relapses occurring between the first MS claim and the index date were identified using the following validated claims-based algorithm [26]. This included any inpatient stay with an MS diagnosis in the primary position or any outpatient claim with an MS diagnosis code in any position followed by a pharmacy or medical claim for dexamethasone, methylprednisolone, prednisolone, prednisone, or adrenocorticotropic hormone within 7 days. The number of patients with one, two, or three or more relapses was measured.

\subsection{Statistical Analysis}

Bivariate descriptive analyses were conducted on all study variables comparing DMT users and their matched controls. Cohort balance after matching was assessed by measuring the standardized difference. Two-sample $t$ tests were used to determine statistical significance for continuous variables. Chi-squared tests were conducted for testing significance in categorical variables. No adjustments were made for multiple comparisons, and the data analysis and bivariate statistics were conducted using WPS version 4.1 (World Programming, UK).

Logistic regression models were used to examine odds of any absenteeism, short-term disability, and long-term disability, separately, in the first calendar year while controlling for baseline clinical characteristics. Generalized linear models with a log link and gamma error distribution were used to assess the costs of absenteeism, short-term disability, and long-term disability among patients who used their benefits in the first calendar year. In all models, baseline clinical variables were adjusted if the standardized differences between the comparison groups (across matched DMT vs matched controls for overall or by ROA) were 10 or above. All models adjusted for the presence of stroke, active hepatitis B (except models of long-term disability outcomes comparing ROA because the sample size was $<10$ for patients with hepatitis B), use of antidepressants, use of benzodiazepines, and use of opioids. Models comparing the use of oral DMTs with other ROAs also adjusted for the presence of relapse in the baseline period and a $10 \%$ difference in the number of days from the first claim with an MS diagnosis to the earliest 
DMT claim. Model assumptions were met for all models, and Chi-square goodness-of-fit statistics were evaluated and it was deemed that the models fit the expected distribution. Multivariable analysis was conducted using R version 3.5.1 (R Foundation for Statistical Computing, Vienna, Austria).

\section{Results}

\subsection{Patient Characteristics}

Among the 88,923 patients with two or more claims for MS and one or more claims for any MS DMT, a total of 3023 patients met the remaining inclusion and exclusion criteria and had absenteeism, short-term disability, or long-term disability eligibility on or after the date of their first DMT claim (Fig. 1). After direct 1:3 (case:control) matching based on demographic characteristics, one DMT user was excluded from the analysis because the patient could not be matched. Among the DMT users, 772 indexed on an oral DMT, 2064 indexed on an injectable DMT, and 186 indexed on an infusion DMT

Baseline demographic and clinical characteristics in postmatched cohorts are summarized in Table 1. DMT users were, on average, 41.4 years old on their index date, and $62.1 \%$ were female. The mean (SD) DCI was $0.4(0.9)$ for DMT users and $0.2(0.5)$ for controls. The mean (SD) time between the first MS claim and the first claim for a DMT was 231.7 (374.7) days. A total of 1063 (35.2\%) DMT users had one or more relapses during the pre-index period.

When DMT users were stratified by ROA, infusion users were younger than injectable users, who were younger than oral users (39.3 years vs 41.3 years vs 42.2 years, all $p<0.05$; Table 1$)$. In addition, infusion users were less likely to be female than either injectable or oral users $(50.5 \%$ vs $62.5 \%$ and $64.1 \%$, both $p<0.01$ ). The distribution of index years was different across ROA due to different FDA approvals. There were baseline differences in comorbidities and concomitant medications, which may have impacted treatment selection. Specifically, stroke was significantly more prevalent among injectable users than oral or infusion users (7.5\% vs $4.8 \%$ or $2.7 \%$, both $p<0.05$ ). Opioid use was significantly higher among injectable users than oral users (36.9\% vs $32.4 \%, p=0.03)$.

The time between the first MS claim and the first claim for a DMT was significantly shorter for injectable users than either oral or infusion users (both $p<0.001$ ), with a mean (SD) duration of 175.0 (287.5) days for injectable users, 348.3 (500.0) days for oral users, and 378.4 (464.0) days for infusion users (Table 1). Possibly as a result of this shorter window of time between the first MS claim and the first DMT claim, the number of patients with one or more relapses during the baseline period was significantly lower for injectable users than either oral or infusion users (33.3\% vs $38.5 \%$ or $41.9 \%$, both $p<0.01$ ). Alternatively, the number of relapses may also be indicative of disease severity and progression.

\subsection{Productivity Loss and Associated Costs among All Disease-Modifying Therapy (DMT) Users}

In the first calendar year of follow-up, a similar percentage of DMT users and controls had one or more absenteeism claims $(78.0 \%$ vs $76.1 \%, p=0.476)$; however, DMT users took a greater mean number (SD) of overall absenteeism hours (313.7 [249.8] h vs 221.8 [124.5] h, $p<0.001)$ and non-recreational absenteeism hours $(153.8$ [241.6] h vs 65.3 [103.1] h, $p<0.001$ ) than control patients (Table 2). DMT users were more likely than controls to have one or more short-term disability claim $(23.2 \%$ vs $5.3 \%, p<0.001)$ or long-term disability claim $(3.1 \%$ vs $0.3 \%, p<0.001)$. In addition, among individuals with one or more short term disability claim, DMT users took more short-term disability days per patient (mean [SD]: 68.8 [53.9] days vs 41.7 [40.2] days, $p<0.001)$ and had longer average individual short-term disability claims (61.8 [50.1] days vs 37.5 [35.8] days, $p<0.001)$ in the first calendar year.

As a comparison, we evaluated the productivity loss among all eligible patients with MS regardless of their history of MS or DMT use. In this cohort, productivity loss was similar to DMT users, with 836 of 1057 (79.1\%) having an absence claim, 1403 of 7278 (19.3\%) having a short-term disability claim, and 180 of $6499(2.8 \%)$ having a long-term disability claim in the first calendar year of observation. The mean (SD) number of non-recreational absence hours was 137.8 (239.0). The mean (SD) length of short-term disability claims was 62.2 (54.4) days, and the mean (SD) length of long-term disability claims was 57.8 (82.0) days.

The estimated incremental indirect costs (DMT users minus controls) of MS among all eligible patients were US\$2007 in absenteeism, US\$2040 in short-term disability, and US\$244 in long-term disability in the first calendar year. Similar trends were observed in the estimated incremental indirect costs of US\$1821 in absenteeism, US\$1842 in short-term disability, and US\$459 in long-term disability costs in the most recent calendar year.

As a sensitivity analysis, we also examined productivity loss and costs in the subset of DMT users $(N=229)$ and controls $(N=522)$ with all three types of eligibility. The trends were similar, and the estimated incremental indirect costs were US $\$ 1732$ in absenteeism, US\$2540 in short-term disability, and US\$897 in long-term disability costs in the first calendar year. The combined mean (SD) indirect cost of absenteeism, short-term disability, and long-term disability was US\$10,146 


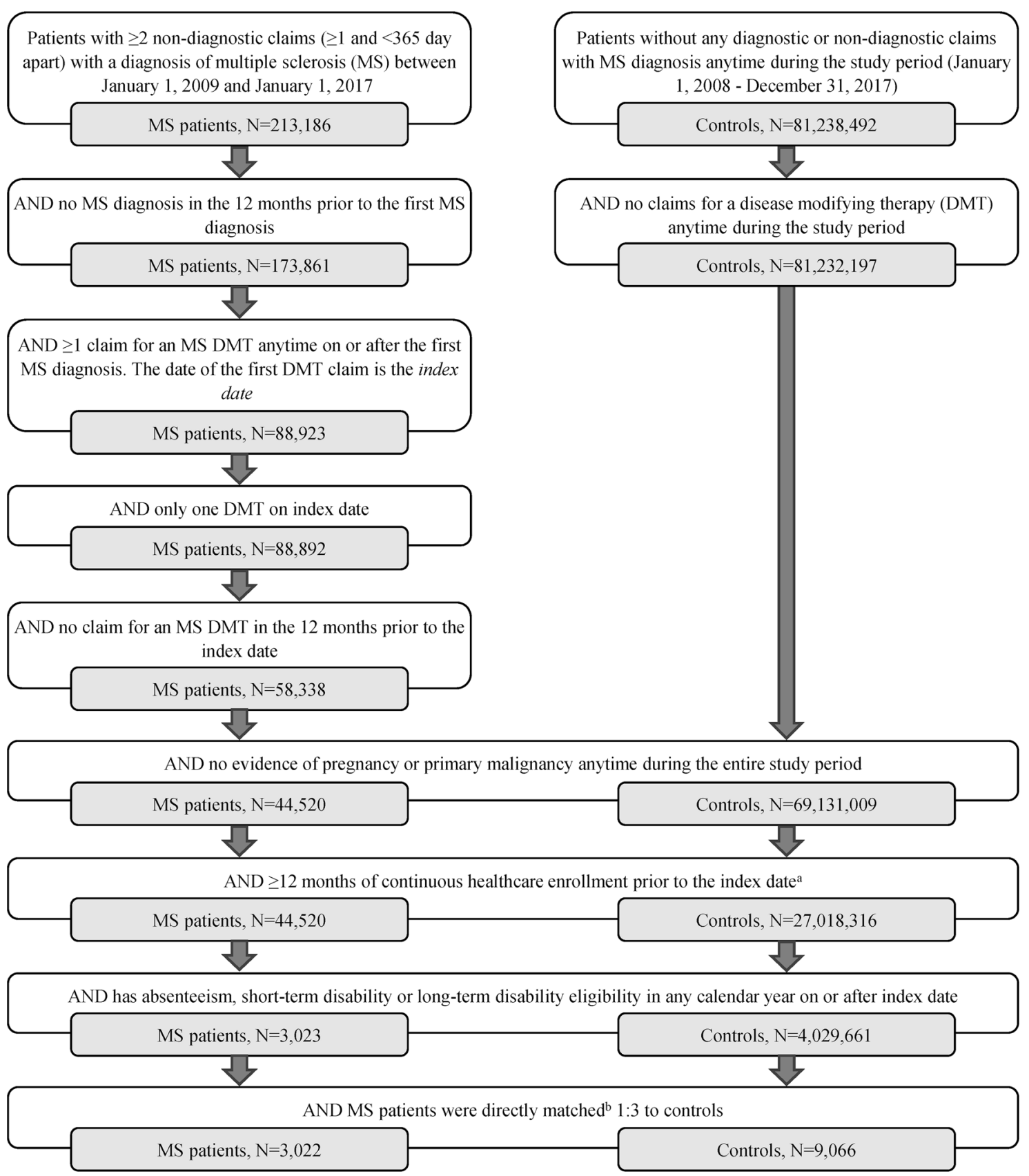

Fig. 1 Primary patient selection. andex date of controls is randomly assigned while maintaining the same distribution of dates as the MS cases. ${ }^{b}$ Patients were matched on age group, sex, health plan type, index year, urban/rural residence, and geographic region

(US\$11,988) for DMT users and US\$4977 (US\$3971) for controls in the first calendar year and US\$9340 (US\$11,978) for DMT users and US\$4895 (US\$3610) for controls in the most recent calendar year.

\subsection{Productivity Loss and Associated Costs by DMT Route of Administration}

When DMT oral and injectable users were compared, their 
Table 1 Baseline demographic and clinical characteristics

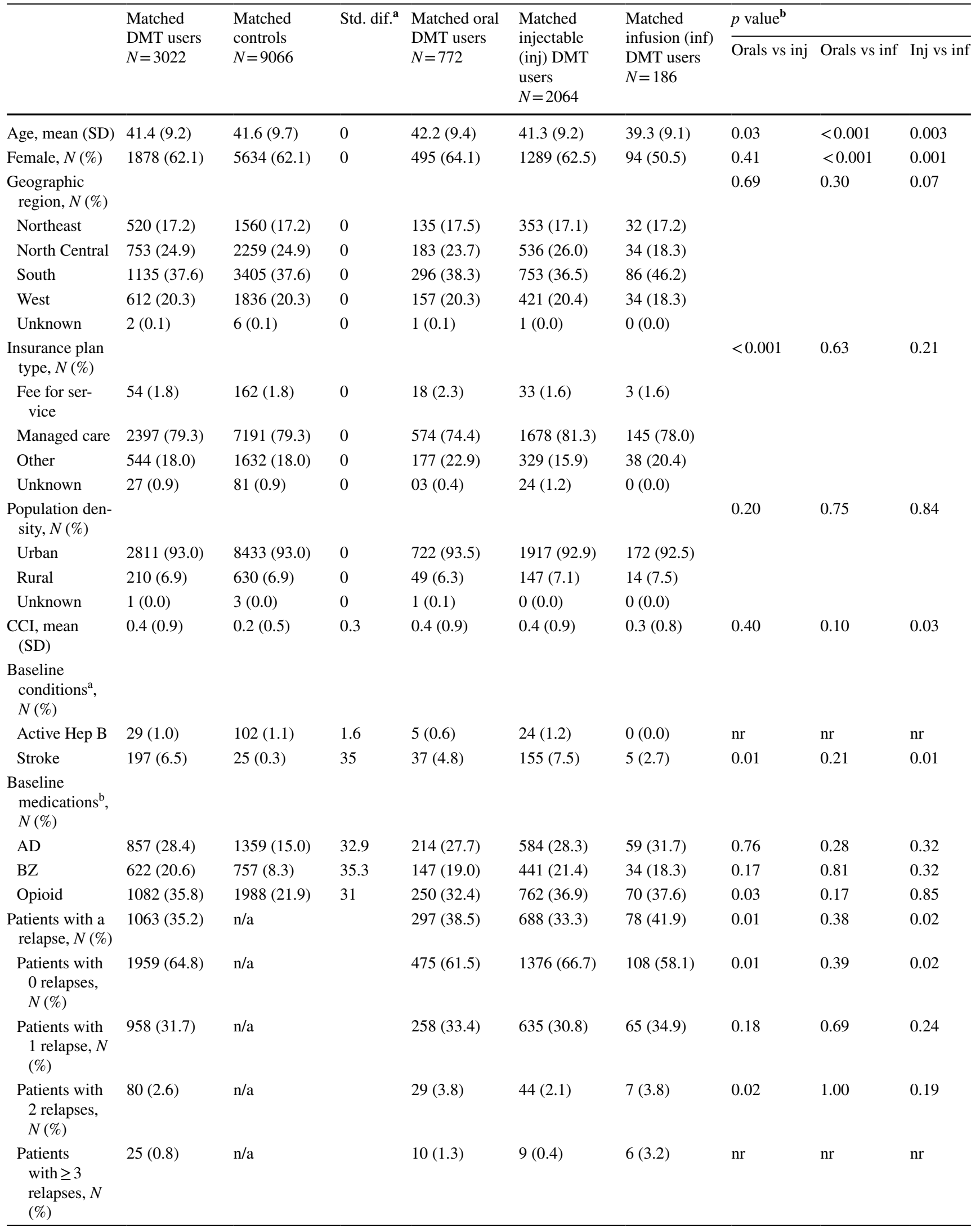


Table 1 (continued)

\begin{tabular}{|c|c|c|c|c|c|c|c|c|c|}
\hline & \multirow{2}{*}{$\begin{array}{l}\text { Matched } \\
\text { DMT users } \\
N=3022\end{array}$} & \multirow{2}{*}{$\begin{array}{l}\text { Matched } \\
\text { controls } \\
N=9066\end{array}$} & \multirow[t]{2}{*}{ Std. dif. ${ }^{a}$} & \multirow{2}{*}{$\begin{array}{l}\text { Matched oral } \\
\text { DMT users } \\
N=772\end{array}$} & \multirow{2}{*}{$\begin{array}{l}\text { Matched } \\
\text { injectable } \\
\text { (inj) DMT } \\
\text { users } \\
N=2064\end{array}$} & \multirow{2}{*}{$\begin{array}{l}\text { Matched } \\
\text { infusion (inf) } \\
\text { DMT users } \\
N=186\end{array}$} & \multicolumn{3}{|l|}{$p$ value $\mathbf{e}^{\mathbf{b}}$} \\
\hline & & & & & & & Orals vs inj & Orals vs inf & Inj vs inf \\
\hline $\begin{array}{l}\text { Days between } \\
\text { first MS claim } \\
\text { and first DMT } \\
\text { claim, mean } \\
\text { (SD) }\end{array}$ & $231.8(374.8)$ & $\mathrm{n} / \mathrm{a}$ & & $348.3(500.0)$ & $175.0(287.5)$ & $378.4(464.0)$ & $<0.001$ & 0.46 & $<0.001$ \\
\hline
\end{tabular}

$A D$ antidepressant, $B Z$ benzodiazepine, $C C I$ Charlson Comorbidity Index, $D M T$ disease-modifying therapy, Hep B hepatitis B, $M S$ multiple sclerosis, $n / a$ not applicable, $n r$ not reported

${ }^{a}$ Cohort balancing after matching was assessed by measuring the standardized difference (Std. dif.)

${ }^{\mathrm{b}}$ Two-sample $t$ tests were used to determine statistical significance for continuous variables and Chi-squared tests were conducted for testing significance in categorical variables

${ }^{\mathrm{c}}$ The presence of second-third-degree atrioventricular block, cholangitis, congestive heart failure, human immunodeficiency virus, long QT syndrome, and progressive multifocal leukoencephalopathy was also assessed during the baseline period and occurred in $<1 \%$ of any cohort

${ }^{\mathrm{d}}$ The use of class 1A anti-arrhythmic, class 3 anti-arrhythmic, and leflunomide was also assessed during the baseline period and occurred in $<1 \%$ of any cohort

Table 2 Productivity loss and associated costs (US\$) in matched DMT users and matched controls in the first calendar year

\begin{tabular}{|c|c|c|}
\hline & $\begin{array}{l}\text { Matched DMT users } \\
N=3022\end{array}$ & $\begin{array}{l}\text { Matched controls } \\
N=9066\end{array}$ \\
\hline Patients with ABS eligibility, $N(\%)$ & $363(12.0)^{*}$ & $899(9.9)$ \\
\hline Patients with an ABS claim, $n(\%)^{\mathrm{a}}$ & $283(78.0)$ & $684(76.1)$ \\
\hline Number of days of follow-up, mean \pm SD (median) $^{b}$ & $186.3 \pm 108.4(186.0)$ & $191.7 \pm 110.3(200.5)$ \\
\hline Overall number of $\mathrm{ABS}$ hours per patient, mean $\pm \mathrm{SD}(\text { median })^{\mathrm{b}}$ & $313.7 \pm 249.8(266.5)^{* *}$ & $221.8 \pm 124.5(220.0)$ \\
\hline Non-recreational number of ABS hours per patient, mean $\pm \mathrm{SD}(\text { median })^{\mathrm{b}}$ & $153.8 \pm 241.6(68.0)^{* *}$ & $65.3 \pm 103.1(38.1)$ \\
\hline Indirect costs per patient among patients with an $\mathrm{ABS}$ claim, mean $\pm \mathrm{SD}(\text { median})^{\mathrm{b}}$ & $\$ 8304 \pm \$ 6613(\$ 7054) * *$ & $\$ 5872 \pm \$ 3296(\$ 5823)$ \\
\hline Indirect costs per patient among patients with $\mathrm{ABS}$ eligibility, mean $\pm \mathrm{SD}(\text { median })^{\mathrm{a}}$ & $\$ 6474 \pm \$ 6779(\$ 5611)^{* *}$ & $\$ 4468 \pm \$ 3814(\$ 4555)$ \\
\hline Patients with STD eligibility, $N(\%)$ & $2696(89.2)^{* *}$ & $7850(86.6)$ \\
\hline Patients with an STD claim, $n(\%)^{\mathrm{a}}$ & $626(23.2) * *$ & $417(5.3)$ \\
\hline Number of days of follow-up, mean \pm SD (median) ${ }^{b}$ & $184.2(104.6)^{*}$ & $201.4(111.0)$ \\
\hline Average number of STD days per claim, mean \pm SD (median) ${ }^{b}$ & $61.8 \pm 50.1(48.0)^{* *}$ & $37.5 \pm 35.8(26.0)$ \\
\hline Average number of STD days per patient, mean \pm SD (median) ${ }^{b}$ & $68.8 \pm 53.9(55.0)^{* *}$ & $41.7 \pm 40.2(29.0)$ \\
\hline Indirect costs per patient among patients with an STD claim, mean \pm SD $(\text { median })^{\mathrm{b}}$ & $\$ 10,200 \pm \$ 7993(\$ 8153)^{* *}$ & $\$ 6177 \pm \$ 5961(\$ 4299)$ \\
\hline $\begin{array}{l}\text { Indirect costs per patient among patients with STD eligibility, mean } \pm \text { SD } \\
(\text { median })^{\mathrm{a}}\end{array}$ & $\$ 2368 \pm \$ 5777(\$ 0)^{* *}$ & $\$ 328 \pm \$ 1950(\$ 0)$ \\
\hline Patients with LTD eligibility, $N(\%)$ & $2346(77.6)$ & 7035 (77.6) \\
\hline Patients with an LTD claim, $n(\%)^{\mathrm{a}}$ & $72(3.1)^{* *}$ & $20(0.3)$ \\
\hline Number of days of follow-up, mean \pm SD (median) ${ }^{b}$ & $215.3 \pm 94.1(211.0)$ & $182.5 \pm 101.0(175.5)$ \\
\hline Average number of LTD days per claim, mean $\pm \mathrm{SD}$ (median) $^{\mathrm{b}}$ & $61.4 \pm 79.2(14.3)$ & $76.5 \pm 75.2(46.3)$ \\
\hline Average number of LTD days per patient, mean $\pm \mathrm{SD}(\text { median })^{\mathrm{b}}$ & $61.6 \pm 79.1(17.0)$ & $85.4 \pm 84.7(47.0)$ \\
\hline Indirect costs per patient among patients with an LTD claim, mean $\pm \mathrm{SD}(\text { median })^{\mathrm{b}}$ & $\$ 9131 \pm \$ 11,725(\$ 2520)$ & $\$ 12,652 \pm \$ 12,559(\$ 6967)$ \\
\hline $\begin{array}{l}\text { Indirect costs per patient among patients with LTD eligibility, mean } \pm \text { SD } \\
(\text { median })^{\mathrm{a}}\end{array}$ & $\$ 280 \pm \$ 2578(\$ 0)^{* *}$ & $\$ 36 \pm \$ 938(\$ 0)$ \\
\hline
\end{tabular}

$A B S$ absenteeism, $D M T$ disease-modifying therapy, $L T D$ long-term disability, $S D$ standard deviation, $S T D$ short-term disability

${ }^{*} p<0.05, * * p<0.001$ Two-sample t-tests were used to determine statistical significance for continuous variables and Chi-squared tests were conducted for testing significance in categorical variables

${ }^{a}$ Among patients with ABS, STD, or LTD eligibility, respectively

${ }^{\mathrm{b}}$ Among patients with an ABS, STD, or LTD claim, respectively 
absenteeism and short-term disability productivity loss and costs were generally similar in the first calendar year (Table 3 and Fig. 2). In the first calendar year of followup, the 67 oral users and 201 injectable users with one or more absenteeism claim claimed a mean (SD) of 274.2 (215.0) and 333.9 (263.3) absenteeism hours, respectively, of which 120.0 (211.6) and 169.1 (255.5) hours were nonrecreational, respectively. The corresponding absenteeism costs were US\$7258 (US\$5691) and US\$8839 (US\$6969) in the first year over a period of 176.0 (112.4) and 188.4 (108.1) days, respectively. The 150 oral users and 433 injectable users with one or more short-term disability claims took, on average, 69.9 (54.4) and 68.8 (50.4) short-term disability hours in the first calendar year over a period of 179.4 (102.5) and 186.1 (106.1) days, respectively. The corresponding mean (SD) short-term disability costs were US\$10,368 (US\$8066) and US\$10,204 (US\$8116), respectively.

Table 3 Productivity loss and associated costs (US\$) in matched DMT users by route of administration in the first calendar year

\begin{tabular}{|c|c|c|c|c|}
\hline & $\begin{array}{l}\text { Orals } \\
N=772\end{array}$ & $\begin{array}{l}\text { Injectables } \\
N=2064\end{array}$ & $p$ value $^{\mathrm{a}}$ & $\begin{array}{l}\text { Infusions } \\
N=186\end{array}$ \\
\hline Patients with ABS eligibility, $N(\%)$ & $88(11.4)$ & $258(12.5)$ & 0.43 & $17(9.1)$ \\
\hline Patients with an ABS claim, $n(\%)^{\mathrm{b}}$ & $67(76.1)$ & $201(77.9)$ & 0.73 & $15(88.2)$ \\
\hline $\begin{array}{l}\text { Number of days of follow-up, mean } \pm \text { SD } \\
\left(_{(\text {median })^{c}}\right.\end{array}$ & $176.0 \pm 112.4(175.0)$ & $188.4 \pm 108.1(198.0)$ & 0.42 & $204.9 \pm 97.4(169.0)$ \\
\hline $\begin{array}{l}\text { Overall number of ABS hours per patient, } \\
\text { mean } \pm \mathrm{SD}(\text { median })^{\mathrm{c}}\end{array}$ & $274.2 \pm 215.0(264.0)$ & $333.9 \pm 263.3(276.4)$ & 0.09 & $219.4 \pm 161.8(186.0)$ \\
\hline $\begin{array}{l}\text { Non-recreational number of ABS hours per } \\
\text { patient mean } \pm \mathrm{SD}(\text { median })^{\mathrm{c}}\end{array}$ & $120.0 \pm 211.6(65.0)$ & $169.1 \pm 255.5(72.0)$ & 0.16 & $99.5 \pm 140.5(50.0)$ \\
\hline $\begin{array}{l}\text { Indirect costs per patient among patients with an } \\
\text { ABS claim, mean } \pm S D(\text { median })^{c}\end{array}$ & $\$ 7258 \pm \$ 5691(\$ 6988)$ & $\$ 8839 \pm \$ 6969(\$ 7316)$ & 0.09 & $\$ 5809 \pm \$ 4283(\$ 4923)$ \\
\hline $\begin{array}{l}\text { Indirect costs per patient among patients with } \\
\text { ABS eligibility, mean } \pm \text { SD (median) }{ }^{\mathrm{b}}\end{array}$ & $\$ 5526 \pm \$ 5852(\$ 4815)$ & $\$ 6887 \pm \$ 7162(\$ 5962)$ & 0.16 & $\$ 5125 \pm \$ 4446(\$ 4659)$ \\
\hline Patients with STD eligibility, $N(\%)$ & $691(89.5)$ & $1850(89.6)$ & 0.92 & $155(83.3)$ \\
\hline Patients with an STD claim, $n(\%)^{\mathrm{b}}$ & $150(21.7)$ & $433(23.4)$ & 0.37 & $43(27.7)$ \\
\hline $\begin{array}{l}\text { Number of days of follow-up, mean } \pm \text { SD } \\
(\text { median })^{c}\end{array}$ & $179.4 \pm 102.5(189.5)$ & $186.1 \pm 106.1(194.0)$ & 0.50 & $182.0 \pm 98.8(171.0)$ \\
\hline $\begin{array}{l}\text { Average number of STD days per claim, } \\
\text { mean } \pm \mathrm{SD}(\text { median })^{\mathrm{c}}\end{array}$ & $64.8 \pm 51.6(50.0)$ & $61.3 \pm 50.4(48.0)$ & 0.46 & $56.4 \pm 40.5(45.0)$ \\
\hline $\begin{array}{l}\text { Average number of STD days per patient, } \\
\text { mean } \pm \text { SD }(\text { median })^{c}\end{array}$ & $69.9 \pm 54.4(53.0)$ & $68.8 \pm 54.8(56.0)$ & 0.83 & $64.6 \pm 43.7(51.0)$ \\
\hline $\begin{array}{l}\text { Indirect costs per patient among patients with an } \\
\text { STD claim, mean } \pm \text { SD (median) }{ }^{c}\end{array}$ & $\$ 10,368 \pm \$ 8066(\$ 7856)$ & $\$ 10,204 \pm \$ 8116(\$ 8301)$ & 0.83 & $\$ 9570 \pm \$ 6482(\$ 7560)$ \\
\hline $\begin{array}{l}\text { Indirect costs per patient among patients with } \\
\text { STD eligibility, mean } \pm \mathrm{SD} \text { (median) }{ }^{\mathrm{b}}\end{array}$ & $\$ 2251 \pm \$ 5687(\$ 0)$ & $\$ 2388 \pm \$ 5836(\$ 0)$ & 0.80 & $\$ 2655 \pm \$ 5471(\$ 0)$ \\
\hline Patients with LTD eligibility, $N(\%)$ & $562(72.8)$ & $1641(79.5)$ & $<0.001$ & $143(76.9)$ \\
\hline Patients with an LTD claim, $n(\%)^{\mathrm{b}}$ & $21(3.7)$ & $47(2.9)$ & 0.30 & $4(2.8)$ \\
\hline $\begin{array}{l}\text { Number of days of follow-up, mean } \pm \text { SD } \\
(\text { median })^{c}\end{array}$ & $194.7 \pm 93.4(174.0)$ & $217.0 \pm 94.2(211.0)$ & 0.37 & $304.0 \pm 44.5(291.0)$ \\
\hline $\begin{array}{l}\text { Average number of LTD days per claim, } \\
\text { mean } \pm \mathrm{SD}(\text { median })^{\mathrm{c}}\end{array}$ & $31.1 \pm 50.1(1.0)$ & $76.3 \pm 86.0(35.0)$ & 0.03 & $45.8 \pm 89.5(1.0)$ \\
\hline $\begin{array}{l}\text { Average number of LTD days per patient, } \\
\text { mean } \pm \mathrm{SD}(\text { median })^{\mathrm{c}}\end{array}$ & $31.7 \pm 49.9(1.0)$ & $76.3 \pm 86.0(35.0)$ & 0.03 & $45.8 \pm 89.5(1.0)$ \\
\hline $\begin{array}{l}\text { Indirect costs per patient among patients with an } \\
\text { LTD claim, mean } \pm \text { SD (median) }{ }^{c}\end{array}$ & $\$ 4701 \pm \$ 7398(\$ 148)$ & $\$ 11,310 \pm \$ 12,753(\$ 5188)$ & 0.03 & $\$ 6782 \pm \$ 13,267(\$ 148)$ \\
\hline $\begin{array}{l}\text { Indirect costs per patient among patients with } \\
\text { LTD eligibility, mean } \pm \mathrm{SD} \text { (median) }{ }^{\mathrm{b}}\end{array}$ & $\$ 176 \pm \$ 1658(\$ 0)$ & $\$ 324 \pm \$ 2850(\$ 0)$ & 0.83 & $\$ 190 \pm \$ 2231(\$ 0)$ \\
\hline
\end{tabular}

$A B S$ absenteeism, $D M T$ disease-modifying therapy, $L T D$ long-term disability, $M S$ multiple sclerosis, $S D$ standard deviation, $S T D$ short-term disability

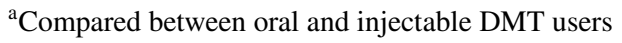

${ }^{\mathrm{b}}$ Among patients with ABS, STD, or LTD eligibility, respectively

${ }^{\mathrm{c}}$ Among patients with an ABS, STD, or LTD claim, respectively 


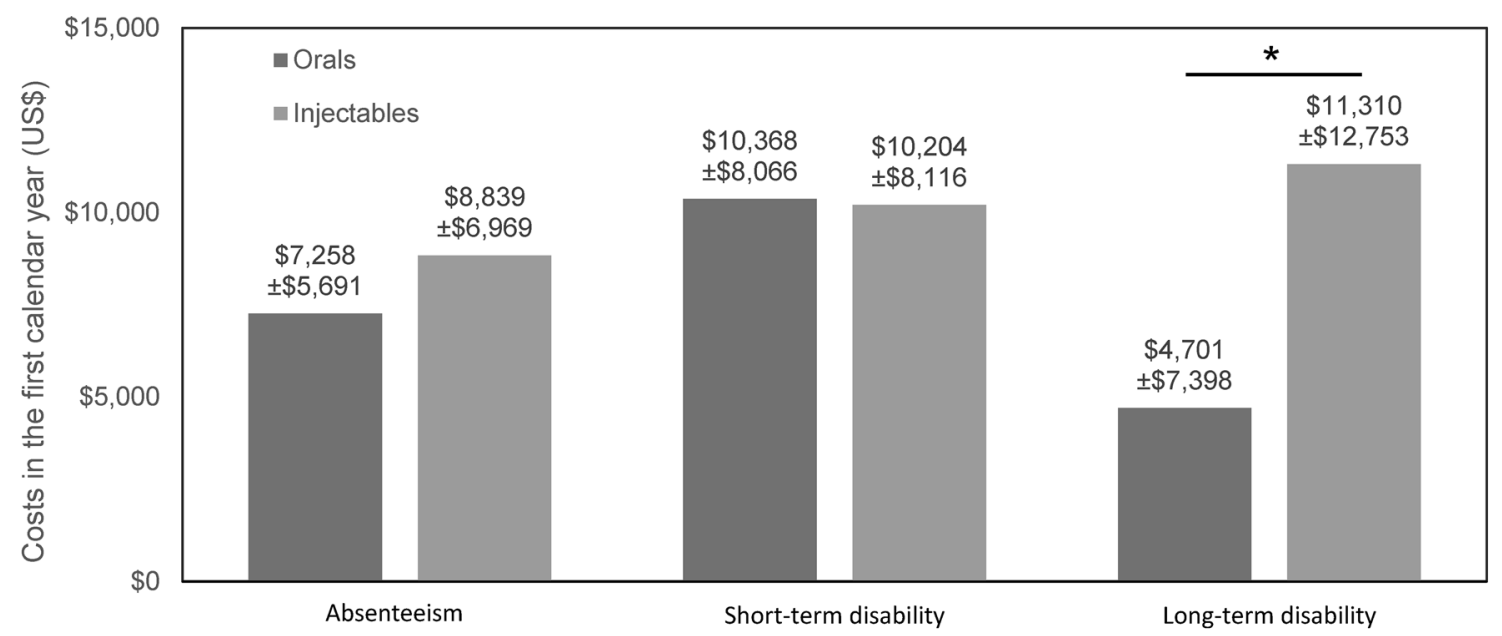

Fig. 2 Comparison of costs associated with work loss between oral and injectable DMT users in the first calendar year of follow-up, calculated among patients with an absenteeism, short-term disability, and long-term disability claim, respectively. ${ }^{*} p<0.05$

While the number of patients with one or more long-term disability claims was low (oral: $n=21$; injectable: $n=47$ ), the mean (SD) number of long-term disability days taken by oral users was less than half the number of days taken by injection users (31.7 [49.9] vs 76.3 [86.0]; $p=0.031)$ in the first year of follow-up (Table 3). The estimated mean long-term disability costs among patients with one or more claims were US\$6609 $(p=0.031)$ lower for oral users than injection users (Fig. 2).

Patients who indexed on infusions were examined separately as these patients are expected to be clinically distinct from those who index on injection or oral medications [10, 11]. Less data was available on infusion users (Table 3 ). During the variable follow-up period, 17 (9.1\%) infusion users had absenteeism coverage, 155 (83.3\%) had short-term disability coverage, and 143 (76.9\%) had long-term disability coverage. In the first calendar year, $15(88.2 \%)$ had one or more absenteeism claims, $43(27.7 \%)$ had one or more short-term disability claims, and 4 (2.8\%) had one or more long-term disability claims. Mean (SD) productivity losses among infusion users with one or more claims were 219.4 (161.8) hours in absenteeism, 64.6 (43.7) days in short-term disability, and 45.8 (89.5) days in long-term disability.

\subsection{Multivariable Analysis}

Multivariable models of odds and costs of using absence, short-term disability, or long-term disability eligibility, which, when adjusted for baseline difference in clinical characteristics, supported the unadjusted analysis comparing DMT users with controls (Supplementary Fig. 1 [see ESM] and Table 2). Differences in costs related to absences, short-term disability, or long-term disability between users stratified by ROA were not significant after multivariable adjustment. The adjusted incremental cost among all DMT users compared with matched non-MS controls was US\$1524 in absenteeism, US\$1514 in short-term disability, and US\$169 in long-term disability (Supplementary Table 2, see ESM).

\section{Discussion}

This real-world analysis examined productivity loss and its associated costs among patients with MS initiating a DMT compared with matched non-MS controls. In addition, productivity loss among patients initiating an oral DMT was compared with that of patients initiating an injectable DMT. Furthermore, productivity loss and its associated costs were examined among patients initiating an infusion DMT.

Compared with control employees without MS, employees with MS who initiated a DMT had higher indirect costs due to absenteeism, short-term disability, and long-term disability in both the first calendar year and the most recent calendar year of follow-up. The adjusted indirect burden of MS among patients initiating a DMT was US\$1524 in absenteeism, US\$1514 in short-term disability, and US\$169 in longterm disability in the first year of follow-up. Among patients with all three types of coverage, the overall unadjusted indirect burden of MS among patients initiating a DMT was US $\$ 5169$. When examined by ROA, patients initiating oral DMTs had less than half the number of days on long-term disability than patients initiating injectable DMTs, and other measures of productivity were similar between ROA cohorts. Additional research is required to determine if there may be an advantage with initiating oral compared with injectable DMTs when making formulary design decisions.

The findings of this study are consistent with trends from earlier analyses. An analysis of MEPS data (1998-2009) 
indicated that patients with MS spent a risk-adjusted average of four times the number of days in bed than controls and were three times less likely to be employed [24]. In addition, a 2009 study by Ivanova et al. comparing employees with MS to matched controls found that patients with MS were more likely to take disability time $(21.4 \%$ vs $5.2 \%$, $p<0.0001)$ and had higher medically related absenteeism costs than controls (US $\$ 1901$ vs US $\$ 1003, p<0.0001$ ) [21]. They reported that the total indirect costs were US\$4352 (2006 USD) higher for patients with MS than controls [21], whereas Birnbaum et al. reported risk-adjusted indirect costs to be US $\$ 801$ lower among DMT-treated versus -untreated patients with MS [27]. In addition, higher adherence to DMTs has been associated with lower relapse rates, productivity losses, and indirect costs [28, 29].

Most research on indirect costs of MS in the US has been conducted on data collected before the approval of any oral medications. One study by Yermakov et al. included patients treated with fingolimod, but they comprised $<1 \%$ of the studied population and were not examined separately [28]. This study expands upon prior analysis by including patients on all DMTs approved before 2017 and by examining patients segmented by ROA. This information may be beneficial to physicians and patients who prioritize work productivity outcomes and who make DMT coverage decisions.

Commonly reported reasons for the use of disability benefits or early retirement among patients with MS are fatigue, reduced motor control, and memory loss/forgetfulness [19, 20]. Severe disease and disease progression have been associated with increased work loss, unemployment, and early retirement, while periods of remission are associated with subsequent work initiation [30, 31]. As relapses are associated with both acute and sustained increases in disability [23], treatment with DMTs is hypothesized to reduce productivity losses by decreasing the frequency and severity of relapses. Annual indirect costs among patients with one or more relapses during the year have been estimated as US\$1429-US\$2714 higher than indirect costs among patients without a relapse [32].

In this analysis, the time between the first MS claim and the first DMT claim was roughly twice as long for patients initiating oral and infusion DMTs compared with those initiating injectable DMTs. This correlated with a higher likelihood of at least one relapse during the baseline period for oral and infusion DMT users compared with injectable DMT users. Despite this delay in treatment, patients initiating oral DMTs had numerically lower absenteeism costs and significantly lower long-term disability costs than patients initiating injectable DMTs before adjusting for baseline clinical characteristics. While reasons for the treatment delay cannot be determined from claims data, insurance, pharmacy, and provider policies have been implicated as barriers to accessing provider-selected DMTs for the treatment of MS [33]. In a survey of patients with MS, $48.7 \%$ reported prior issues accessing their prescribed DMT. Of those, $41 \%$ reported going without any DMT and 30\% reported experiencing at least one relapse during the time of the barrier [33]. MS presents heterogeneously and progresses at different rates, warranting a need for unencumbered access to DMTs, irrespective of ROA.

In the ROA subanalysis, we compared oral users with injection users but not infusion users. This approach was selected because the initial examination of baseline characteristics suggested that patients receiving infusion DMTs were a distinct population from those receiving oral or injection DMTs. This decision was supported by a review of the literature on MS treatment patterns, which found that there are two primary therapeutic approaches for treatment sequencing: induction and escalation. Induction therapy utilizes highly effective therapies (specifically alemtuzumab and mitoxantrone) in the first-line setting to achieve rapid control of highly active disease, whereas escalation therapy initiates patients on lower-risk therapies (such as dimethyl fumarate, glatiramer acetate, interferon, or teriflunomide) and reserves infusion therapies for breakthrough disease $[10,11]$. In this analysis, only $6 \%$ of patients initiated infusion DMTs, and those who did were younger, less likely to be female, and more likely to have had relapses prior to treatment. These characteristics are consistent with those of patients who would be candidates for induction therapy and, therefore, clinically distinct from patients treated with an escalation therapy approach who initiated oral or injection DMTs.

\subsection{Limitations}

The limitations of this study include those inherent in any retrospective analysis. First, this study was limited to only individuals with commercial health coverage and work loss eligibility. Consequently, results may not be generalizable to MS patients with other insurance, without health insurance coverage, or without coverage for work loss. Second, the potential for misclassification of MS status, demographic characteristics, and clinical characteristics is present, as patients were identified through administrative claims data as opposed to medical records. Third, disease severity is not available in claims records and, therefore, could not be adjusted for in the analysis. Fourth, administrative claims data are subject to data coding limitations and data entry errors. Fifth, there was no specific data available to specify the reasons for hours missed from work; thus, the use of non-recreational absence hours does not necessarily imply the MS was the cause of the absence.

Another limitation is that index date assignment for controls was done only once, which may make the analysis 
sensitive to randomly occurring major health events, which could result in either overestimation or underestimation of indirect costs among controls. In addition, costs were estimated based on an average fixed hourly wage and did not account for potential differences in industry or job-specific variations that may have occurred between cohorts. The analysis was also not structured to evaluate the impact of index year on the outcomes, and a final limitation is that ROA grouping was assigned by index medication and did not account for discontinuation or switching to a DMT with a different ROA. Prior research has estimated that $53-61 \%$ of patients initiating DMT are adherent to their index medication for at least a year [34, 35], so it is possible that some of the patients may have changed their ROA during the followup period. Additional research is required to understand how treatment discontinuation and switching impact work loss and interpretation of this analysis.

\section{Conclusion}

There is a significant indirect economic burden in employees with MS, including an adjusted difference of US\$1524 in absenteeism, US $\$ 1514$ in short-term disability, and US\$169 in long-term disability in the first year of follow-up. Future work should examine potential modifiable contributors to the high indirect costs among MS patients, of which ROA may be one.

Acknowledgements The authors received medical writing support from Jessamine Winer-Jones of IBM Watson Health, Cambridge, MA, USA, and editorial support from Peloton Advantage, LLC, an OPEN Health company, Parsippany, NJ, USA, sponsored by Bristol-Myers Squibb company, Princeton, NJ, USA. This study was funded by Celgene, a Bristol-Myers Squibb Company.

\section{Declarations}

Funding This study was funded by Celgene, a Bristol-Myers Squibb company.

Conflict of interest CP is employed by Bristol-Myers Squibb Company; RM and MT were employed by Bristol-Myers Squibb Company at the time the study was conducted. GK is employed by IBM Watson Health as a consultant and received funding from Bristol-Myers Squibb Company to conduct this study; MB and IS were employed by IBM Watson Health at the time the study was conducted. NG is a paid consultant of Bristol-Myers Squibb Company.

Ethics approval All database records are statistically de-identified and certified to be fully compliant with US patient confidentiality requirements set forth in the Health Insurance Portability and Accountability Act of 1996. Because this study used only de-identified patient records and did not involve the collection, use, or transmittal of individually identifiable data, Institutional Review Board approval to conduct this study was not necessary.
Consent to participate Not applicable.

Consent for publication Not applicable.

Availability of data and material The data that support the findings of this study are available from IBM Watson Health. Restrictions apply to the availability of these data, which were used under license for this study.

Code availability Not applicable.

Author contributions All authors contributed to the study conception and design. Material preparation and data analysis were performed by Gilwan Kim and Ila Sruti. All authors contributed to the development of the first draft and read and approved the final manuscript.

Open Access This article is licensed under a Creative Commons Attribution-NonCommercial 4.0 International License, which permits any non-commercial use, sharing, adaptation, distribution and reproduction in any medium or format, as long as you give appropriate credit to the original author(s) and the source, provide a link to the Creative Commons licence, and indicate if changes were made. The images or other third party material in this article are included in the article's Creative Commons licence, unless indicated otherwise in a credit line to the material. If material is not included in the article's Creative Commons licence and your intended use is not permitted by statutory regulation or exceeds the permitted use, you will need to obtain permission directly from the copyright holder. To view a copy of this licence, visit http://creativecommons.org/licenses/by-nc/4.0/.

\section{References}

1. Tullman MJ. Overview of the epidemiology, diagnosis, and disease progression associated with multiple sclerosis. Am J Manag Care. 2013;19(2 Suppl):S15-20.

2. Wallin MT, Culpepper WJ, Campbell JD, Nelson LM, LangerGould A, Marrie RA, et al. The prevalence of MS in the United States: a population-based estimate using health claims data. Neurology. 2019;92(10):e1029-40.

3. Hunter SF. Overview and diagnosis of multiple sclerosis. Am J Manag Care. 2016;22(6 Suppl):s141-50.

4. Bandari DS, Sternaman D, Chan T, Prostko CR, Sapir T. Evaluating risks, costs, and benefits of new and emerging therapies to optimize outcomes in multiple sclerosis. J Manag Care Pharm. 2012;18(9):1-17.

5. Thompson AJ, Banwell BL, Barkhof F, Carroll WM, Coetzee T, Comi G, et al. Diagnosis of multiple sclerosis: 2017 revisions of the McDonald criteria. Lancet Neurol. 2018;17(2):162-73.

6. Lublin FD, Reingold SC, Cohen JA, Cutter GR, Sørensen PS, Thompson AJ, et al. Defining the clinical course of multiple sclerosis: the 2013 revisions. Neurology. 2014;83(3):278-86.

7. Cross AH, Naismith RT. Established and novel diseasemodifying treatments in multiple sclerosis. J Intern Med. 2014;275(4):350-63.

8. Rae-Grant A, Day GS, Marrie RA, Rabinstein A, Cree BAC, Gronseth GS, et al. Comprehensive systematic review summary: disease-modifying therapies for adults with multiple sclerosis. Neurology. 2018;90(17):789.

9. Rae-Grant A, Day GS, Marrie RA, Rabinstein A, Cree BAC, Gronseth GS, et al. Practice guideline recommendations summary: disease-modifying therapies for adults with multiple sclerosis: report of the Guideline Development, Dissemination, and 
Implementation Subcommittee of the American Academy of Neurology. Neurology. 2018;90(17):777-88.

10. Freedman MS, Selchen D, Prat A, Giacomini PS. Managing multiple sclerosis: treatment initiation, modification, and sequencing. Can J Neurol Sci. 2018;45(5):489-503.

11. Pardo G, Jones DE. The sequence of disease-modifying therapies in relapsing multiple sclerosis: safety and immunologic considerations. J Neurol. 2017;264(12):2351-74.

12. Garcia-Dominguez JM, Munoz D, Comellas M, Gonzalbo I, Lizan L, Polanco SC. Patient preferences for treatment of multiple sclerosis with disease-modifying therapies: a discrete choice experiment. Patient Prefer Adherence. 2016;10:1945-56.

13. Utz KS, Hoog J, Wentrup A, Berg S, Lammer A, Jainsch B, et al. Patient preferences for disease-modifying drugs in multiple sclerosis therapy: a choice-based conjoint analysis. Ther Adv Neurol Disord. 2014;7(6):263-75.

14. Wilson LS, Loucks A, Gipson G, Zhong L, Bui C, Miller E, et al. Patient preferences for attributes of multiple sclerosis diseasemodifying therapies: development and results of a ratings-based conjoint analysis. Int J MS Care. 2015;17(2):74-82.

15. Adelman G, Rane SG, Villa KF. The cost burden of multiple sclerosis in the United States: a systematic review of the literature. J Med Econ. 2013;16(5):639-47.

16. Gold R, Toumi M, Meesen B, Fogarty E. The payer's perspective: what is the burden of MS and how should the patient's perspective be integrated in health technology assessment conducted for taking decisions on access to care and treatment? Mult Scler. 2016;22(2 Suppl):60-70.

17. Kobelt G, Berg J, Atherly D, Hadjimichael O. Costs and quality of life in multiple sclerosis: a cross-sectional study in the United States. Neurology. 2006;66(11):1696-702.

18. Zwibel HL, Smrtka J. Improving quality of life in multiple sclerosis: an unmet need. Am J Manag Care. 2011;17(Suppl 5):S139-45.

19. Cadden M, Arnett P. Factors associated with employment status in individuals with multiple sclerosis. Int J MS Care. 2015;17(6):284-91.

20. Coyne KS, Boscoe AN, Currie BM, Landrian AS, Wandstrat TL. Understanding drivers of employment changes in a multiple sclerosis population. Int J MS Care. 2015;17(5):245-52.

21. Ivanova JI, Birnbaum HG, Samuels S, Davis M, Phillips AL, Meletiche D. The cost of disability and medically related absenteeism among employees with multiple sclerosis in the US. Pharmacoeconomics. 2009;27(8):681-91.

22. Hirst C, Ingram G, Pearson O, Pickersgill T, Scolding N, Robertson $\mathrm{N}$. Contribution of relapses to disability in multiple sclerosis. J Neurol. 2008;255(2):280-7.

23. Lublin FD, Baier M, Cutter G. Effect of relapses on development of residual deficit in multiple sclerosis. Neurology. 2003;61(11):1528-32.
24. Campbell JD, Ghushchyan V, Brett McQueen R, Cahoon-Metzger $\mathrm{S}$, Livingston T, Vollmer T, et al. Burden of multiple sclerosis on direct, indirect costs and quality of life: National US estimates. Mult Scler Relat Disord. 2014;3(2):227-36.

25. Simpson H. Short-term disability benefits. Compensation and Working Conditions (US Bureau of Labor Statistics, Summer 1997). 1997;52-6. https://www.bls.gov/opub/mlr/1997/article/ short-term-disability-benefits.htm.

26. Chastek BJ, Oleen-Burkey M, Lopez-Bresnahan MV. Medical chart validation of an algorithm for identifying multiple sclerosis relapse in healthcare claims. J Med Econ. 2010;13(4):618-25.

27. Birnbaum HG, Ivanova JI, Samuels S, Davis M, Cremieux PY, Phillips AL, et al. Economic impact of multiple sclerosis diseasemodifying drugs in an employed population: direct and indirect costs. Curr Med Res Opin. 2009;25(4):869-77.

28. Yermakov S, Davis M, Calnan M, Fay M, Cox-Buckley B, Sarda $\mathrm{S}$, et al. Impact of increasing adherence to disease-modifying therapies on healthcare resource utilization and direct medical and indirect work loss costs for patients with multiple sclerosis. J Med Econ. 2015;18(9):711-20.

29. Ivanova JI, Bergman RE, Birnbaum HG, Phillips AL, Stewart $\mathrm{M}$, Meletiche DM. Impact of medication adherence to diseasemodifying drugs on severe relapse, and direct and indirect costs among employees with multiple sclerosis in the US. J Med Econ. 2012;15(3):601-9.

30. Jones E, Pike J, Marshall T, Ye X. Quantifying the relationship between increased disability and health care resource utilization, quality of life, work productivity, health care costs in patients with multiple sclerosis in the US. BMC Health Serv Res. 2016;16:294.

31. Julian LJ, Vella L, Vollmer T, Hadjimichael O, Mohr DC. Employment in multiple sclerosis. Exiting and re-entering the work force. J Neurol. 2008;255(9):1354-60.

32. Parise H, Laliberte F, Lefebvre P, Duh MS, Kim E, Agashivala N, et al. Direct and indirect cost burden associated with multiple sclerosis relapses: excess costs of persons with MS and their spouse caregivers. J Neurol Sci. 2013;330(1-2):71-7.

33. Simacek KF, Ko JJ, Moreton D, Varga S, Johnson K, Katic BJ. The impact of disease-modifying therapy access barriers on people with multiple sclerosis: mixed-methods study. J Med Internet Res. 2018;20(10):e11168.

34. Burks J, Marshall TS, Ye X. Adherence to disease-modifying therapies and its impact on relapse, health resource utilization, and costs among patients with multiple sclerosis. Clinicoecon Outcomes Res. 2017;9:251-60.

35. Munsell M, Frean M, Menzin J, Phillips AL. An evaluation of adherence in patients with multiple sclerosis newly initiating treatment with a self-injectable or an oral disease-modifying drug. Patient Prefer Adherence. 2017;11:55-62. 